\title{
Why Pakistan Must Break-into the Knowledge Economy
}

\section{Rashid Amjad*}

\begin{abstract}
The author emphasizes in this paper that this was the moment in Pakistan's economic trajectory for it to learn to leap frog technologically from a labor intensive economy, by passing the intermediate stages of resource based and scale based activities, to a knowledge based economy. A knowledge based economy is one that bases its growth not on increasing capital or land or labor inputs, but on knowledge. The transition required is considerable, the author points out.
\end{abstract}

There is growing recognition that the global economy is increasingly driven by "knowledge" rather than the traditional factors of production. Pakistan's Medium-Term Development Framework (MTDF) 2005-2010 and Vision 2030 Approach Paper both recognize the key role of knowledge in economic growth when they describe the goal of transforming Pakistan by 2030 into a "Developed, industrialized, just and prosperous Pakistan through rapid and sustained development ... by deploying knowledge inputs". ${ }^{1}$

In my presentation today at this Second Annual Conference on Management of the Pakistan Economy being held at the Lahore School of Economics I would like to explore this issue further. ${ }^{2}$ I start by trying to define what is really meant by a "knowledge economy" especially in the context of a developing country like Pakistan. I then go on to discuss the imperatives of why Pakistan must break-into the knowledge economy. Finally I examine what would constitute the key elements of a strategy for Pakistan to move into the knowledge economy drawing also upon Pakistan's experience in developing the ICT sector, a major pillar of the knowledge economy.

\footnotetext{
* The author is Director, Policy Planning, Employment Sector, International Labour Organization (ILO), Geneva.

${ }^{1}$ See Preamble to the Approach Paper: Strategic Directions to Achieve Vision 2030, Planning Commission, Government of Pakistan, Islamabad, February 2006.

${ }^{2}$ In this paper I have gone somewhat beyond the issues and analysis that I raised in my presentation at the Conference.
} 


\section{Understanding the knowledge economy}

Is there any precise way that we can define the knowledge economy especially in the context of a developing country like Pakistan?

Let us start with knowledge which has been broadly defined in terms of information (access and use), learning (education and skills) and capacity to adapt to rapid and continuous change. Similarly the knowledgebase of an economy has been defined as "the capacity and capability to create and innovate new ideas, thoughts, processes and products, and to translate these into economic value and wealth."

Using these two definitions as building blocks a knowledge economy has been defined as one where production and services are increasingly based on knowledge-intensive activities i.e. greater reliance on intellectual capabilities than on physical inputs or natural resources. Such an economy is characterised by an accelerated pace of technical and scientific advance as well as rapid obsolescence, and expansion of a knowledge economy is driven by the emergence of new products and industries.

In an increasingly competitive global economy, knowledge serves as a major source of competitiveness and knowledge creation results from greater investment and importance to science, research, technology and innovation and the use of the computer and the internet to generate, share and apply knowledge.

It can be argued that many of these changes can be viewed as a continuation of advances that were also witnessed starting from the industrial revolution and indeed even before that. What then is different? Cowan and Paal (2000) suggest that the rate of change has accelerated in the last three decades which also implies a faster response to them. They argue that "because there are so many simultaneous changes we now see a constellation emerging rather than a simple gradual evolution of an existing one." What this implies is that the contributions of knowledge are very much reflected in the dynamics that drive present day economies (and indeed they suggest that it is better to describe such economies as "knowledge-driven" rather than just "knowledge-based").

\section{Measuring the knowledge economy}

If attempts to precisely define the knowledge-economy pose difficulty then it is not surprising that both measuring it and tracking its progress pose equal if not greater difficulty. 
The OECD has in its publication Science, Technology and Industry Scoreboard, starting in 1999, attempted to benchmark knowledge-based economies and developed indicators to track its progress. This may provide some insights into how one may measure the knowledge economy.

According to the OECD (1999) while all industries are to some extent dependent on knowledge inputs some industries rely more on knowledge than others. Knowledge-based industries are then identified as those which are relatively intensive in their inputs of technology and/or human capital and defined as technology-intensive industries. In addition to the manufacturing sector the OECD (1999) has also tried to capture the right service sectors which are more knowledge-intensive. This has proven more challenging and the OECD (2005) has identified knowledge-based services to include post and telecommunication services, finance and insurance services and education and health.

Combining manufacturing and services the OECD benchmarks knowledge economies as follows:

Tota1 Technology and knowledge-based industries = High-technology manufactures + Medium-high-technology manufactures + Post and telecommunication services + finance and insurance services + education and health ${ }^{3}$

The other important part of this equation is the investment or key inputs needed to generate knowledge which would drive growth in the knowledge economy. These are identified by OECD (2005) as follows:

Investment in knowledge $=$ Expenditure on R\&D (research and development $)+$ software + higher education

Tracking these indicators in OECD countries has come up with some interesting findings:

- According to OECD (1999) over the period 1985-95 knowledgebased industries have been outpacing growth of GDP for many years in virtually all OECD countries i.e. their share has been growing as compared to the others. In 1995 it was more than 50 per cent, up from 45 per cent in 1985. There was a slight dip in this growth in 2000-2001 but according to OECD (2005) "the long term-trend towards a knowledge-based economy continues."

\footnotetext{
${ }^{3}$ Total with "market" services excludes education and health.
} 
- Investment in knowledge (comprising expenditure on R\&D, software and higher education) in the OECD area reached around 5.2 per cent of GDP in 2001, compared to around 6.9 per cent for investment in machinery and equipment.

What then is a knowledge-based or knowledge-driven economy? The first is its capacity to produce high and high to medium technologyintensive products. Technology so defined therefore covers both manufactures at the frontier of innovation but also the ability to handle efficiently and improve complex processes. The second is to have the range of services which are knowledge-intensive in terms of both the use and creation of knowledge.

And what drives a knowledge economy? A partial explanation is the expenditure on research and development, higher education and software development.

Clearly these are not comprehensive or fully satisfactory definitions but they do provide us some indicators by which we may try to navigate our way in defining and measuring a knowledge economy.

\section{Benchmarking Pakistan in the knowledge economy}

It may be somewhat presumptuous to benchmark Pakistan in terms of a knowledge-based economy given its very poor basic human resource indicators. A large part of the labor force is illiterate. In 2003-04 around 48 per cent of the population 10 years of age and above was illiterate of which males were 36 percent and females 60 per cent. The mean years of schooling for adults over the age of 15 was 3.9 years compared to 8.5 for the Philippines, 6.5 for Thailand and 5.1 for India. One-third of the labor force in 2003-04 had an education level below matric.

The share of the manufacturing sector in GDP has increased very little since the late 1960s and only a spurt in economic growth post 19992000 has increased the share to 18 per cent in 2004-05. This should be compared with the significant increases of 280 per cent in Malaysia, 170 per cent in the case of Thailand and 120 per cent in the case of Republic of Korea over the past 30 years.

According to UNIDO (2005) the share of medium-or-high technology goods in overall manufacturing value-added in 2002 is much lower in Pakistan, around 35 per cent, compared with around 58 per cent for India and China and 61 per cent for the Republic of Korea and 65 per 
cent for Malaysia. Similarly the share of medium-or-high technology products in manufacturing exports in 2002 remains low at 10 per cent in Pakistan compared to 20 per cent for India, 46 per cent for China, 70 per cent for Republic of Korea and 76 per cent for Malaysia.

UNIDO (2005) also has developed an industrial-cum technological advance (ITA) index. In 2002 Pakistan was 0.104 on the index compared to 0.198 for India, 0.235 for China, 0.338 for the Republic of Korea and 0.269 for Malaysia.

As the Vision 2030 Approach (2006) paper points out traditional industries such as food (13.8 per cent) and textiles ( 24 per cent) still account for the overwhelming share of manufacturing output in Pakistan and industries based on modern technologies such as machinery, both electrical and non-electrical, and automobiles account for just 4.4 and 4.7 per cent respectively. Even though chemical industries accounted for around $15.2 \mathrm{per}$ cent, most of the chemical industrial output is concentrated in low-tech and low value added industries. Also while Pakistan has a small share of the three industries with the largest share of world trade i.e. electronics and electrical machinery, pharmaceuticals and automobiles, Pakistan has been doing well in these in recent years with improving scales and supporting vendor industries.

Till recently Pakistan had ignored or given very little emphasis to higher education, science and technology and research and development. In Pakistan tertiary enrolments (per cent of population age 17-23 years) levels are about 4 per cent compared 10.5 per cent in India and 28.2 per cent in Malaysia. On the index of availability of scientists and engineers, Pakistan's rank is 61 out of 93 countries. In 2000 Pakistan had 100 scientists and engineers per million population, compared with 149 in India, 350 in China and 500 in Malaysia.

According to the Global Competitiveness Report (2005) Pakistan's position was 87 on the technology index (includes sub-indices for innovation, technology transfer and ICT) compared to India (63), China (62), Republic of Korea (9), Malaysia (27) and Thailand (43) with the United States being on top.

Clearly all these indicators point to the fact that in terms of a knowledge-economy Pakistan clearly comes out rather poorly in comparison with its South Asian neighbour India and even more sharply in comparison with some of the fast growing South-East Asian economies. 


\section{Why Pakistan must move into the knowledge economy?}

Here we must try to differentiate between two sets of issues. The first is the need to improve on Pakistan's rather poor basic human development indicators i.e. literacy, education and skill levels of its work force and social infrastructure. This in itself would lead to significant increases in productivity and improve competitiveness of its economy.

But trying to move into the knowledge economy is clearly much more than this. Reverting to the OECD indicators it means transforming the structure of the economy such that the manufacturing sector and especially the export sector produces high and high to medium technology-intensive products. Here even the UNIDO (2005) figure for Pakistan of 35 per cent of present manufacturing producing high and medium technology goods may be an exaggeration, even though this would still work out as only around 6 per cent of GDP. This is because many of the industries which are included in this category are either highly protected and inefficient, as for example auto and auto-parts, or produce low-value added goods as for example chemicals mentioned earlier.

The better indicator is in terms of the more competitive export market products. Here Lall and Weiss (2004) provide some interesting insights. They convincingly show that Pakistan's world market share of technology-intensive manufactured exports remains very low and that its export structure is dominated by low-technology and low sophisticated products. Even in the case of textile and clothing exports where Pakistan continues to be a major player, it is losing market share in many of the most dynamic global textile and clothing exports.

In terms of services expenditure on higher education, especially science subjects, this has only recently starting going up with an eventual target of 1 per cent of GDP by 2020 . The contribution of software development and services still remain very low. Even in financial services Pakistan's performance has been mixed and its share in exports almost negligible.

There are three basic reasons why Pakistan needs to change this situation and move into the global economy:

- First technology-intensive exports are the most fast growing and dynamos of change, in particular electronic products related to IT. These products enjoy very high income elasticity of demand and have pervasive, links through the industrial and technological 
system. Similarly, as the experience of the developed or the OECD countries shows knowledge-intensive industries (which includes technology-intensive) are the fastest growing and their share in national output is increasing.

- Second, that competitiveness in the global economy is closely dependent on investment in knowledge and in remaining at the frontier of new technology, producing new products and improving the quality of existing ones.

- Third, knowledge defined in terms of both the production and use of ideas as the wave of "new" growth theories propound is a significant "endogenous" factor in determining economic growth and raising productivity (Romer, 1990 and 1993 and Lucas, 1993). For developing countries that are not on the technological frontier, larger initial stocks of human capital thus enable them to adapt new ideas and acquire technological capability. It also accelerates the need for continuous learning to keep up with the pace of change.

\section{Pakistan's strategy to enter the knowledge economy}

The MTDF 2005-10 and Vision 2030 Approach paper set out the strategic vision to develop Pakistan into a knowledge economy by committing increased resource allocation for: (i) higher education with enrolment at the tertiary level increasing from around 4 per cent (17-23 age group) to 8 per cent in 2010 and 20 per cent in 2022 with efforts focussed at enhancing quality and encouraging private sector involvement and ensuring continued increase in funding until 1 per cent of GNP is devoted to this sector; (ii) skills development to make Pakistan's labor force globally competitive including re-introducing technology streams in secondary education to gradually aim for enrolment figures of 50 per cent; (iii) science and technology and research and development (R\&D) and to refocus efforts to those areas considered strategic for developing a knowledge-based economy and to encourage collaboration among public research institutions, universities and clusters of industries; and (iv) improvements in ICT infrastructure to ensure that such communications and multimedia infrastructure is state-of-the-art and able to keep pace with rapid advances.

In addition, the strategy aims at a sectoral approach for raising the knowledge content in agriculture, manufacturing and services especially through access to finance and technology to smaller entrepreneurs and 
manufacturers, with SMEs being encouraged to move along the value-chain and knowledge-intensive activities and exploiting the huge unprocessed resources in agriculture.

The Vision 2030 Approach paper also envisages "a massive structural change rather than a marginal change" in the manufacturing sector with a shift in the production paradigm to technology and knowledge based industrialization from traditional industries and services, through an export led strategy rather than inefficient import substitution. The Vision 2030 Approach paper recognizes the empirical evidence that such diversification is unlikely to take place without directed government action and policies to embed private initiative that encourages restructuring, diversification, and technological upgradation beyond what can be generated by market forces alone. These policies will be spelt out in more detail in the final vision document.

Beyond manufacturing, the Vision 2030 Approach paper also speaks of a new paradigm to affect the service industry and make Pakistan ready and willing to play a larger role in the new regime and provisions under the General Agreement on Trade in Services (GATS) especially in the areas of banking, financial services and transport and communication. The measures to be taken are not spelt out.

Finally, the MTDF 2005-10 identifies a list of knowledge economy indicators which include share of high-tech products in exports, enrolment of science, maths and engineering students at the tertiary level, number of technicians produced annually as a per cent of school leavers and an innovation index based upon R\&D institutions, $\mathrm{PhD}$ numbers in science and engineering, research publications and patents.

\section{Pakistan's performance in the ICT sector}

Before we examine Pakistan's envisaged strategy to become a knowledge economy it may be useful to look at Pakistan's experience in the development of the software industry in Pakistan which is considered to be a major pillar of the knowledge economy. The box below shows the opportunities that exist for the development of the software sector and the current state of the sector in Pakistan. 


\section{Opportunities: ICT-Software Sector}

- Outsourcing is a US $\$ 225$ billion a year industry

- India's software exports in 2005 were US \$ 17.5 billion

- Pakistan in the range of US $\$ 150$ to 200 million (of which US \$ 48.5 million transacted through the State Bank in 2004-05)

- India faces infrastructure and price pressures

- Can Pakistan take advantage?

\section{Pakistan ICT- Software Sector}

- 500 registered companies

- 70 ISO certified with 30 due in June 2005

- One CMM Level 5 company, one level 4 , another 5 to be assessed at level 3

- 6000-8000 IT Professionals engaged in software exports out of a total of 57,000

- 5500 IT graduates produced per year

Source: Malik (2006)

Pakistan's progress in software development has, to say the least, been disappointing despite some positive developments in recent years. Compared to neighboring India's exports of US \$ 17.5 billion Pakistan has managed to export on a comparable basis between US $\$ 150$ to $\$ 200$ million. While it produces around 5500 IT graduates per year, except for a few leading institutions, they are of poor quality. A large number of the few high quality graduates find it much more attractive to seek employment overseas rather than within Pakistan despite the relatively high salaries offered to such graduates by domestic companies.

Also, although Pakistan has a large pool of educated Englishspeaking school-leavers and graduates it has not been able to tap outsourcing opportunities including Call Centres which again India has done very successfully.

While this is not the place to go into a detailed analysis of the factors which have been responsible for the poor performance of Pakistan's IT sector, it is clear that these primarily relate to the number and quality of the IT graduates it produces and the difficulties in retaining the good quality graduates it produces. Pakistan's lack of success is also blamed on the perception of foreigners of the law and order and security conditions in the 
country which makes foreigners reluctant to travel to Pakistan and undertake joint projects with domestic companies. Another important factor has been the lack of domestic demand as a large segment of the corporate sector still does not rely on the use of IT technology and the services of domestic IT firms.

\section{Some Important Conclusions}

While it is encouraging to see that Pakistan has realized the importance of transforming itself into a knowledge economy and spelled out a detailed strategy to achieve this objective, it clearly has a long way to go.

It is perhaps important to realize that just increasing resources for investment in higher education and skills and in science and technology and research and development, important as it is, would not be sufficient. Indeed the author in another paper (Amjad, 2005) has raised the important question of whether the development of a well-educated and skilled labor force is sufficient for any economy to graduate from labor-intensive to higher value-added and technologically advanced sectors.

The key issue here is the quality of the graduates you produce. Here a mechanical number game to meet targets of graduates and doctorates could prove in the long term to be very harmful. A realistic view must be taken of the capacity of the higher education sector to produce good quality outputs and targets adjusted to meet this critical goal. Then, the question of retaining these good quality graduates in the country needs to be tackled.

While it is also clear that the aim should be to diversify the economy into a more knowledge-intensive, higher value-added sectors, the role the government could play in this and the incentive structure to be put in place to achieve this needs to be carefully worked out. While one can envisage a role of the government especially in the provision of physical and social infrastructure, beyond that it is difficult to envisage what exactly this would be in the global economy in which you are committed to reducing tariffs and other subsidies. The major player would then have to be the private sector- large, medium and small firms as well as farmers with different size holdings- which would drive the process. The whole issue of developing competitiveness and identifying and exploiting "niche markets" in the global economy would be the real challenge for the private sector in Pakistan. So far, Pakistan's entrepreneurs have a reputation ("animal spirits") for seeking markets and profits both domestically and abroad but it has done so under a fair degree of domestic protection. How would it perform in a more competitive environment? Only time would tell. 
The point being made is that it would be a big mistake to try to "target" sectors and "industries" in efforts to transform yourself into a knowledge economy. Although not quite stated as such, both the MTDF 2005-10 and Vision 2030 Approach paper seem to imply this. If this is so, then this approach needs to be rectified.

Similarly, Pakistani planners suffer from a delusion that you could forecast the demand and supply of both highly educated and skilled labor. Again this would be a big mistake if investment in higher education and skills are guided by some long-term manpower projections. In a global economy with fast changing technology, the only thing you can be right about is that any such manpower projections would be wrong. There is no easy answer to this as it cannot be all left to just market forces. But ultimately it would have to be guided primarily by the market and what the government could do is to set up a robust monitoring system which would identify skills shortages in the economy and help guide investment by both the private and public sector in skills development. Similarly, as much as possible local education and training institutions should be given the autonomy to respond to changing market needs.

Finally, the pursuit of a knowledge economy can only take place if individuals feel that they will be valued and respected for the knowledge they possess. In this the role of a well functioning, equitable, efficient and just labor market is essential and in which fundamental workers' rights are recognized and fully respected. Sadly, this is not being done in Pakistan today and there are considerable shortcomings in the existing legislation especially as regards freedom of association and collective bargaining as well as in labor inspection. These shortcomings need to be rectified.

To conclude, we have explored in this presentation what the imperatives are for Pakistan to develop into a knowledge economy. It is good to see that Pakistani policy makers are aware of this challenge and are developing a strategy to achieve this goal. But a number of important questions still need to be faced. This paper has tried to address just a few of them. Hopefully this will spark further debate and discussion. 


\section{References}

Amjad, Rashid, 2005, Skills and Competitiveness: Can Pakistan break out of the Low-level Skills Trap, paper presented at the $21^{\text {st }}$ Annual General Meeting of the Pakistan Society of Development Economists (Iqbal Memorial Lecture), Islamabad 19-21 ${ }^{\text {st }}$ December 2005 (Forthcoming Special Issue Pakistan Development Review).

Cowan, Robin and Geert van de Paal, 2002, European Innovation Policy in the Knowledge-Based Economy, Brussels, European Commission, DG-Enterprises, 2000.

Friedman, Thomas, 2005, The World is Flat: A Brief History of the Globalized World in the $21^{\text {st }}$ Century, Allen Lane, Penguin Books, London, England

International Social Science Journal, 2002, The Knowledge Society, No. 171, Blackwell Publishing/UNESCO.

Lall, Sanjay and John Weiss, 2004, Industrial Competitiveness: The Challenge for Pakistan, ADB Institute-Pakistan Resident Mission, ADB Pakistan, Resident Mission, Islamabad.

Lucas, R.F., 1993, "Making a miracle", in Econometrica (New Haven. Conn), Vol.61, No. 2, 1993.

Malik, Hamid, 2006, 'IT Sector in Pakistan: Major Constraints to growth with special emphasis on Human Resources Development', Background paper prepared for the ILO's Employment and Skills Forum (2006), Islamabad, (unpublished).

Manse11, Robin and Uta When, 1998, Knowledge Societies: Information Technology for Sustainable Development, United Nations Commission on Science and Technology Development, United Nations, Oxford University Press, New York.

OECD, 1999, Science, Technology and Industry Scoreboard 1999: Benchmarking Knowledge-Based Economies, Brussels (www.oecd.org/sti/scoreboard).

OECD, 2005, Science, Technology and Industry Scoreboard 2005, Brussels 
Planning Commission, Government of Pakistan, 2006, Approach Paper Strategic Directions to Achieve Vision 2030, Islamabad (www.pakistan.gov.pk/ministries/planning and development-ministry/ vision $2030 \mathrm{htm}$.)

Planning Commission, Government of Pakistan, 2005, Medium Term Development Framework 2005-10, Planning Commission, Islamabad.

Romer, P., 1993, "Two strategies for economic development: Using ideas and producing ideas", in Proceedings of the World Bank Annual Conference on Development Economics 1993 (Washington D.C., World Bank).

Romer, P., 1990, "Endogenous technological change", in Journal of Political Economy (Chicago), Vol. 98, No. 5, Part 2.

UNIDO, 2005, Industrial Development Report 2005: Capability Building for Catching Up-Historical, Empirical and Policy Dimension, Vienna (www.unido.org/doc/5156. 